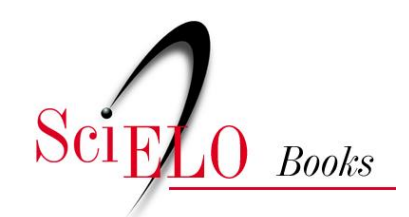

\title{
Seduepb
}

\section{6 - Dimensões para a análise e desenvolvimento de Tecnologia Social}

\author{
Renato Dagnino
}

DAGNINO, R. Dimensões para a análise e desenvolvimento de Tecnologia Social. In: Tecnologia Social: contribuições conceituais e metodológicas [online]. Campina Grande: EDUEPB, 2014, pp. 185-206. ISBN 978-85-7879-327-2. Available from SciELO Books $<\underline{\text { http://books.scielo.org }>\text {. }}$

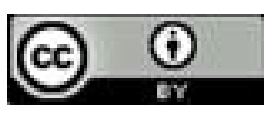

All the contents of this work, except where otherwise noted, is licensed under a Creative Commons Attribution $\underline{4.0 \text { International license. }}$

Todo o conteúdo deste trabalho, exceto quando houver ressalva, é publicado sob a licença Creative Commons Atribição 4.0.

Todo el contenido de esta obra, excepto donde se indique lo contrario, está bajo licencia de la licencia $\underline{\text { Creative }}$ Commons Reconocimento 4.0. 


\section{6}

\section{Dimensões para a análise e desenvolvimento de Tecnologia Social ${ }^{38}$}

\section{Introdução}

Este documento retoma aspectos contidos em outros trabalhos ${ }^{39}$ que elaborei com a mesma finalidade - propor recomendações de natureza metodológica para a realização do Projeto IDRC (International Development Research Center) - cujo conteúdo serviu de fundamentação para várias das ideias aqui expostas.

Seu título sugere que o desenvolvimento de Tecnologia Social (TS) supõe uma análise de alternativas tecnológicas existentes, sejam elas consideradas tecnologias sociais ou tecnologias convencionais. E essa análise pode ser organizada a partir de dimensões contextuais que orientem o desenvolvimento de TS, segundo critérios sociotécnicos capazes de materializar um dos seus objetivos hoje mais urgentes e focados: o fortalecimento da Economia Solidária (ES). Pelo recém-mencionado, deve-se entender que o termo dimensões está relacionado ao procedimento de análise enquanto que seria mais aconselhável reservar o de critérios para o processo de desenvolvimento. Mas, também, que ambos os termos guardam uma estreita relação.

Ao retomar aqui aspectos contidos em outros documentos e ideias que vêm surgindo em reuniões do Projeto, busquei sintetizá-los sob a forma de orientações mais específicas e direcionadas à realização das nossas atividades imediatas, situadas no plano da análise.

38 Este documento é resultado do estágio atual da discussão em curso no âmbito da equipe do GAPI-Unicamp (Grupo de Análise de Política de Inovação) e irá sendo alterado à medida em que forem surgindo novas contribuições além daquelas realizadas por Milena Serafim, Carol Bagattolli e Rafael Dias. Ele é de responsabilidade do autor, daí o fato de ser escrito na primeira pessoa do singular.

39 Os mais recentes, citados em ordem de importância para o entendimento do presente documento, são: (1) Mais insumos metodológicos para a análise, a pesquisa e o desenvolvimento de Tecnologia Social; (2) Em direção a uma teoria crítica da tecnologia; (3) Por que Capacitação em C\&T para o Desenvolvimento Social?; (4) Um insumo para os Estudos Sociais da Ciência e Tecnologia: o que é isso que hoje chamamos de Ciência \& Tecnologia? 
Antes, porém, introduzo uma ideia que sintetiza, de modo esquemático e idealizado, o processo de desenvolvimento de TS a partir das condições relativas aos contextos sociotécnicos ${ }^{40}$ correspondentes às tecnologias convencional e social. Ela decorre do fato de que o desenvolvimento de tecnologias alternativas e a TS, em particular, ainda não possui um referencial abrangente que ajude a apontar um caminho adequado. Falta-nos uma racionalidade crítica, alternativa àquela da tecnologia convencional.

Esse referencial abrangente ou racionalidade crítica alternativa que necessitamos para orientar o desenvolvimento de TS e, no estágio e situação em que nos encontramos para analisar experiências relacionadas à sua concepção, reaplicação etc., e cuja elaboração tem orientado o meu esforço em trabalhos anteriores é o que eu vou denominar adiante de "operador".

\section{A ideia de "operador"}

Com a noção de "operador", procuro explorar o fato conhecido de que o desenvolvimento de tecnologia convencional é o resultado de uma construção sociotécnica que, por se verificar ao longo de um processo tão complexo e sistêmico de coorganização, teve a ele associado por Hughes (1983) o conceito de "tecido sem costuras", tal a dificuldade em identificar e separar, no contexto em que ele ocorre, o "social" do "técnico" e do "econômico".

Mas para formular a noção de "operador", foi necessário ir ainda mais além desse conceito já em si revolucionário para os que estudavam até então as relações entre ciência, tecnologia e sociedade. Foi necessário juntar elementos que permitissem perceber que esse modo de desenvolvimento e esse "tecido sem costuras" que se nos afigura hoje de maneira naturalizada e a-histórica é uma "aparência" que, como outras tantas manifestações típicas do capitalismo, encobre uma "essência" que, para enfrentar o desafio de desenvolver e mesmo estudar TS, temos que desvelar.

A materialização dessa percepção se dá mediante a proposição de um "operador", uma instrumentalização geradora que, idealizada tendo em

40 Com a expressão “contexto sociotécnico", quero me referir ao conjunto de condicionantes que em outros âmbitos disciplinares se costuma designar como sendo de natureza econômica, política, social, histórica, cultural, étnica, sexual, ecológica etc., e que incidem no processo de construção sociotécnica ou de Adequação Sociotécnica tal como o entendemos no campo cognitivo que exploramos. 
vista o desenvolvimento de sistemas tecnológicos baseados em TS, seja capaz de auxiliar na concepção de uma metodologia para estudar a TS.

Uso aqui a expressão sistema tecnológico para enfatizar que, tal como proposto por Hughes (1983), no plano descritivo-explicativo para denotar um conjunto complexo que associa conhecimentos científicos, dispositivos técnicos, jurídicos, políticos, econômicos, organizacionais etc., e se define mediante uma reorganização do mundo fisico e social de maneira a equacionar problemas visualizados como tais pelos integrantes do sistema, devemos entender a TS, agora no plano normativo que caracteriza o nosso trabalho, como um sistema.

Isto é, que devemos entender o desenvolvimento de TS como um processo de concepção coletiva que reúne e coordena elementos heterogêneos - atores sociais (movidos por valores e interesses, ao mesmo tempo particulares e prenhes de alianças políticas) e recursos (de poder político, cognitivos, econômicos) com características e competências diferentes - e que tende a uma estabilização conjunta do "social" e do "técnico" etc., que conduz a arranjos híbridos, nos quais os elementos tecnológicos e sociais (sociotécnicos) estão indissociavelmente misturados.

$\mathrm{Ou}$ ainda, que devemos entender que o "desenvolvimento de uma TS" só ocorrerá de fato quando a imbricação desses diferentes elementos, que de acordo com nossa percepção crítica acerca da Neutralidade e do Determinismo da tecnociência ${ }^{41}$, incorporam interesses e valores do contexto sociotécnico em que ela ocorre, enseje uma estabilização. Uma estabilização semelhante àquela que caracteriza a ideia de sistema tecnológico conforme descrito pela literatura sobre construção sociotécnica para os artefatos tecnológicos que nos chamaríamos de convencionais ou capitalistas. Mas, ao mesmo tempo distinta, ou simétrica, dado que marcada por interesses e valores opostos, no plano do antagonismo intrínseco ao capitalismo, aos do capital.

O "desenvolvimento de uma TS", que idealmente ocorrerá, ao longo de uma trajetória, que tenho denominado de Adequação Sociotécnica, só estará completado, quando se tornar impossível "recortar", no âmbito de um tecido uniforme e "sem costuras", que se irá constituir, os pedaços do "social", do "técnico" e do "econômico" que se irão co-organizando. Esse tecido se apresentará de uma forma semelhante àquela, naturalizada, que envolve os sistemas tecnológicos capitalistas que conhecemos.

41 Embora prefira o uso do conceito de tecnociência (DAGNINO, 2008) ao de "Ciência e Tecnologia", utilizo por uma questão de comunicação com a literatura que trata da tecnologia, em especial a que se refere à TS, alternadamente, conforme me parece conveniente, os conceitos de tecnociência e tecnologia. 
O desenvolvimento de tecnologias alternativas, entendidas como aquelas que apresentam características que as distinguem daquelas (convencionais) que são desenvolvidas para ou pelas empresas, tem sido realizado, seja pelos participantes do movimento de tecnologia apropriada seja pelos que hoje se engajam no de TS, em função de algum tipo de desconforto em relação à tecnologia convencional ou a situações que envolvem ou propiciam a sua concepção.

Como costuma ocorrer em situações em que algum tipo de desconforto suscita a ação de algum ator social, o processo de desenvolvimento de TS é marcado por iniciativas esparsas, de natureza frequentemente individual. Mais importante, elas não se orientam para satisfazer alguma demanda (entendida como uma necessidade apoiada por poder de compra) previamente identificada; o que faz que seu processo de desenvolvimento tenda a ser bem menos direcionado e conscientemente estimulado do que aquele que tem tido como resultado a TS.

Esse fato, que distingue o processo de desenvolvimento de tecnologia convencional daquele da TS, faz com que ele tenda a ser condicionado pelas idiossincrasias de cada ator social que, em geral, de modo individual e fora de seu contexto rotineiro de atuação profissional, se mobiliza baseado em princípios éticos ou morais (e não em busca do lucro) visando a alterar aquela situação.

Dada a importância e urgência que envolve o desenvolvimento de TS, considero que ele não pode estar sujeito a uma lógica dessa natureza. Portanto, e sem desprezar o que é essencial ao movimento de TS - seu engajamento com os princípios da Economia Solidária e da autogestão e o compromisso de muitos de seus integrantes com a construção de uma "outra sociedade" - considero necessário que se procure conferir um caráter sistemático e racional ao processo de desenvolvimento de TS.

É coerentemente com essa opinião, e correndo o risco de ser mal-entendido, mas buscando justamente o contrário, que me atrevo a elucubrar (ou divagar), no plano abstrato das ideias, mas sem perder de vista o objetivo de desenvolver TS, sobre como se poderia chegar a conferir aquele caráter sistemático e racional a esse processo.

Começo minha incursão externando minha opinião de que para tanto é necessário conceber um "mecanismo" que - claro que no plano das idealizações - "opere" o desenvolvimento de TS. Esse "mecanismo" que vou denominar "operador", quando "aplicado sobre" uma tecnologia convencional e levando em conta os aspectos do contexto (ou ambiente) sociotécnico em que a ela está inserida, seria capaz de apontar um caminho seguro para a sua desconstrução e posterior reconstrução 
tendo em vista outro contexto sociotécnico, coerente com a Economia Solidária. Em outras palavras, algo que ajudasse a materializar a proposta Adequação Sociotécnica que leva ao desenvolvimento de TS.

$\mathrm{Na}$ base da proposição acerca da concepção de um "operador" capaz de - no plano abstrato das ideias - operar com essas características, estão três conjuntos de ideias; todos eles sintetizados mais adiante neste capítulo. O primeiro é o relacionado à proposta Adequação Sociotécnica, que formulei inicialmente em 2002. O segundo se refere aos conceitos de Instrumentalização Primária e Secundária formulados por Feenberg. O terceiro se relaciona à idealização do processo de coorganização que teria dado origem ao contexto sociotécnico capitalista, realizada num trabalho mais recente.

Essa proposição - simples e intuitiva - parte, então, de duas suposições. A primeira é a de que é possível resumir a enorme quantidade e variedade de fatores que condicionam o processo de desenvolvimento de tecnologia convencional assimilando-os a um "operador" que as explicitasse de forma sistemática e compreensível ${ }^{42}$. Ou seja, que "traduzisse" o complexo processo de construção sociotécnica que origina a tecnociência capitalista (ou o enorme conjunto de artefatos tecnológicos que a constituem) em função dos valores e interesses hegemônicos nos ambientes onde é gerada. Ou ainda, que "materializasse" a concepção contrária à da Neutralidade e do Determinismo explicitando, para cada artefato tecnológico capitalista ${ }^{43} \mathrm{o}$ "como, quando, aonde e quem" que relaciona os condicionantes dos respectivos contextos às suas características.

A segunda suposição é a de que esse "operador" pudesse agir também no sentido contrário. Isto é, que ao esclarecer o processo de construção sociotécnica da tecnologia convencional, pudesse esclarecer também o processo análogo, mas em certo sentido simétrico, de desenvolvimento

42 Algo que operasse de forma semelhante a uma Instrumentalização Secundária tendo por base o resultado de uma prévia Instrumentalização Primária.

$43 \mathrm{O}$ uso alternativo e sinonímico das expressões "tecnologia convencional", "tecnologia capitalista", "tecnociência capitalista" e, agora, "artefato tecnológico capitalista", não deve ser entendido como a adoção de uma perspectiva filiada ao que se conhece como "Determinismo Social". Ele apenas reconhece a ideia fundacional do conceito de TS, de que seu desenvolvimento se pauta pela percepção de que suas características devem estar adaptadas a um conjunto de necessidades e interesses coerentes com o que se enfeixa no conceito de Economia Solidária. E de que, simetricamente, como anteriormente indicado, existe uma insatisfação por parte de quem desenvolve TS em relação ao contexto sociotécnico que preside o desenvolvimento de tecnologia convencional e que envolve a sua utilização condicionando as suas características. 
de TS. E, por esta via, operar sobre uma dada tecnologia convencional situada num dado contexto sociotécnico indicando como conduzir o processo de Adequação Sociotécnica, entendido como aquele que leva ao desenvolvimento de TS.

Alguém poderia dizer, e estaria quase certo, que tal "operador" já existe. E que já foram realizados muitos estudos a partir de um marco analítico-conceitual relativamente bem formulado e testado a partir de estudos de caso acerca do processo de construção sociotécnica "capitalista”. E, há também outros estudos, ainda que em menor número (como o de Noble acerca do desenvolvimento da máquina-ferramenta de controle numérico), que evidenciam como a adoção pelos engenheiros de critérios "não técnicos" atuaram no sentido de inibir o controle dos operários sobre o processo de trabalho. Existem, finalmente, outros, que politizando o tema até o ponto de argumentar a existência de um caráter de classe na orientação da construção sociotécnica (vale a redundância: "capitalista") mostram como a mobilização de atores até então excluídos do processo logrou sua radical reorientação (como é o caso dos trabalhos sobre "racionalização subversiva" de Feenberg que analisam os programas de Aids).

Mas, sem tirar a razão daqueles que argumentam nesse sentido, insisto em nosso compromisso de mais longo prazo que não se restringe ao dificil trabalho de documentar e analisar experiências de geração e reaplicação de TS, demanda um passo mais ambicioso. Trata-se de, como indicado acima, conceber um "operador" que indique um caminho mais seguro para o desenvolvimento de TS.

Para exemplificar, tomo a TS bem conhecida, no Brasil, das cisternas concebidas para a coleta da água da chuva em comunidades rurais. Como se sabe, ela pode ser considerada como uma alternativa a um sistema centralizado de distribuição de água obtida mediante a captação em algum manancial de superfície ou da perfuração de um poço, e armazenada em tanques de grande capacidade através de bombeamento.

É possível imaginar uma situação remota no tempo que - hipotética e teoricamente - teria dado origem a cada um desses sistemas tecnológicos como sendo aquela em que um grupo humano, situado numa localidade às margens de um manancial, fizesse o uso da água para satisfazer suas necessidades mediante seu deslocamento até ele ou mediante o transporte da água até as moradias. E, à medida que o adensamento populacional em torno dessa primeira localidade fosse ocorrendo, tornasse-se contraproducente para as famílias recém-chegadas. 
Identificar os elementos do contexto sociotécnico que levaram, de forma mais ou menos generalizada, no noroeste do planeta e no âmbito de modos de produção ainda não identificáveis como capitalistas, a adoção do sistema centralizado de distribuição de água é o exercício que se propõe como inicial para a concepção do "operador".

Fica ao "leitor aplicado", como se escrevia nos meus textos de escola, a tarefa de prosseguir com essa análise e utilizar a proposta aqui apresentada para tratar outros casos similares.

\section{A matriz TS e as dimensões de análise}

O resultado buscado pode ser visualizado como uma matriz de dupla entrada em que, na primeira coluna, estejam listadas as dimensões e, na primeira linha, as tecnologias sociais escolhidas para colocar em marcha o Projeto (as demais alternativas tecnológicas porventura existentes - convencionais ou sociais - embora não apareçam na matriz, serão também analisadas a partir de procedimentos a serem indicados).

São duas as entradas possíveis na matriz que se idealiza como resultado da análise proposta por este documento.

1. A entrada na coluna correspondente a uma TS qualquer (TSi) proporciona a sua "posição" relativa a cada uma das dimensões (Di) e pode indicar, na última linha, um agregado indicativo de sua "posição" referente às demais TS.

2. A entrada na linha correspondente a uma dimensão qualquer (Di) proporciona a "posição" relativa de cada uma das TS e pode indicar, na última coluna, um agregado indicativo da "aderência" ou "pertinência" do conjunto das TS a esta dimensão.

Essas duas entradas podem ser entendidas (e ao que tudo indica, serão) como insumos para as duas "leituras" que serão realizadas e organizadas sob a forma de documentos do Projeto. Sem pretender superestimar a importância da proposta que se faz neste documento, chamo a atenção que o número de documentos passíveis de serem elaborados é de $\mathrm{t}+\mathrm{d}$, sendo t o número de tecnologias e $\mathrm{d}$ o de dimensões.

\section{As dimensões e seus conjuntos}

Nesta seção, sem a pretensão de esgotar o assunto e sim de iniciar um processo necessariamente iterativo e interativo, submeto aos colegas algumas dimensões classificadas em oito conjuntos. 
Ressalto que sua consideração deve dar-se lembrando que a América do Sul continua sendo a região mais desigual do mundo e que a exclusão social, numa situação em que mais da metade da População Economicamente Ativa (PEA) se encontra na informalidade e em que o setor formal tenderá a seguir sendo incapaz de absorver os que buscam emprego, demanda ações direta e especificamente voltadas à inclusão social. Elas deverão transcender àquelas de tipo compensatório e, também, as relacionadas à mera qualificação dos excluídos para uma cada vez menos provável absorção pela economia formal.

A inclusão social, entendida não como a "inclusão" na economia formal, e sim na ES, supõe criar as condições para que algumas das atividades de produção de bens e serviços, usualmente realizadas por empresas e que crescentemente são "transferidas" de modo precarizado para o setor informal, possam ser levadas a cabo por EESs. Para tanto, será necessário completar e adensar cadeias produtivas hoje situadas na economia informal de modo a transformá-la na ES, que cresce rapidamente e está cada vez mais apoiada pelos governos da região, ES. Mas satisfazer as necessidades materiais dos hoje excluídos, que nela serão incluídos, dos trabalhadores que passarão a integrar os EESs, é apenas a "ponta do iceberg". Abaixo dela, do tecido produtivo, são levadas a cabo atividades hoje realizadas por outros agentes econômicos, em geral empresas privadas, que produzem bens e serviços que poderão ter sua produção absorvida pela ES. E, mais importante, submergida, encontra-se uma parte do iceberg correspondente a uma grande e variada demanda por bens públicos que o Estado deve proporcionar a todos os cidadãos e que atualmente o faz utilizando do seu poder de compra em beneficio das empresas.

Essa parte de baixo do iceberg (além é claro da sua "ponta") só pode ser explorada caso conte com o desenvolvimento de TS que proporcione sustentabilidade econômica, cultural e ambiental aos EESs. A geração da tecnologia que necessitam esses arranjos produtivos terá que ser apoiada de modo distinto daquele usado para apoiar a $\mathrm{P} \& \mathrm{D}$ realizada pelas e para as empresas, que vêm recebendo, há muito tempo, vultoso, variado e continuado apoio estatal.

O apoio aos EESs demanda novos modos de regulação da transferência de recursos e orientação do poder de compra do Estado para aquisição dos bens e serviços que eles podem produzir. Além do fato de que seria um contrassenso por parte do Estado não estimular um setor da economia (e uma parte de população) no qual, o governo vem alocando recursos crescentes através de seus programas compensatórios, o apoio citado implicaria outras vantagens evidentes. 


\section{Conjunto Descrição}

1) Tipo de produto:

Bens: Características (insumos, bens de consumo, bens de capital) e Destino (autossubsistência das famílias, comunidade envolvida, ES, economia formal, público em geral via poder de compra do Estado);

Serviços: Características (...) e Destino (...);

2) Características do sistema de propriedade dos meios de produção (coletiva, privada, pública);

3) Características do processo de trabalho em que se insere a TS.

\section{Conjunto Conhecimento}

4) Participação de pesquisadores no desenvolvimento da TS (grau de interação com a comunidade de pesquisa);

5) Grau em que os "usuários" possuem conhecimento ancestral ou adquirido e formas como se deu a sua monopolização pelo capital;

6) Balanço entre conhecimento "tradicional" e "científico" embutido na TS;

7) Participação dos "usuários” no desenvolvimento da TS;

8) Dinâmica de aprendizado na construção da TS.

\section{Conjunto Sustentabilidade Econômica}

9) Contribuição para criar, adensar e completar cadeias produtivas da ES;

10) Distância (autonomia) relativa em relação à economia formal (grau de integração na cadeia produtiva da economia formal ES);

11) Potencialidade de conformação de um sistema sociotécnico autônomo (ES).

\section{Conjunto Sustentabilidade Ambiental}

12) Modo como a tecnologia afeta o meio ambiente (degrada, não afeta, recupera) 


\section{Conjunto Sustentabilidade Cultural}

13) Características em relação às práticas culturais da comunidade envolvida;

14) Características em relação a práticas de autogestão;

15) Potencialidade quanto ao empoderamento dos "usuários";

16) Relação da tecnologia com questões de gênero, raça, classe social etc.

\section{Conjunto Sustentabilidade Política}

17) Potencialidade de ter "seu" sistema sociotécnico fomentado mediante:

Diretamente, via recursos públicos para $\mathrm{P} \& \mathrm{D}$, investimento etc. Indiretamente, via poder de compra do Estado;

18) Potencialidade de angariar apoio da comunidade de pesquisa;

19) Potencialidade de angariar apoio de outros segmentos e movimentos sociais.

\section{Conjunto Alternativas Tecnológicas}

20) Existência de alternativas tecnológicas (Tecnologia Convencional ou Tecnologia Social)

21) Possibilidade de desconstrução da Tecnologia Convencional em questão (características da Tecnologia Convencional em relação aos conceitos de instrumentalização primária e secundária);

22) Relação com as modalidades de Adequação Sociotécnica.

\section{Conjunto Entorno Sociotécnico}

23) Características do entorno sociotécnico. Pode ajudar aqui a tipologia das seis situações típicas proposta (1. limite econômico, 2. limite político, 3. limite do econômico x político, 4. gradiente tecnológico, 5 . gradiente regulatório ou de mercado, 6 . gradiente político)

24) Possibilidade de compatibilização entre vantagens cooperativas, necessidades e demandas 


\section{Conjunto Dinâmica Sociotécnica}

25) Elementos que explicam o funcionamento ou não funcionamento, o sucesso ou o fracasso da tecnologia

26) Processos de co-construção que configuram a ontologia das "coisas sociais" e das "coisas tecnológicas"

27) Marco tecnológico ${ }^{44}$ (technological frame) que indica como são construídos os problemas e as soluções (como o problema é definido, negociado, processado, trabalhado etc.)

28) Grupos sociais relevantes ${ }^{45}$ : suas características e modo de atuação no processo de estabilização do $\operatorname{artefato}^{46}$

\section{A dimensão "Possibilidade de desconstrução da Tecnologia Convencional”}

Considero que muitas das dimensões acima nomeadas precisam ser mais esclarecidas. É o que tento fazer nesta seção e nas que se seguem.

Trato aqui dos conceitos de instrumentalização primária e secundária. Embora eles tenham a TC como referência, parecem-me essenciais para materializar a ideia contida em nossa definição mais simples de Tecnologia (para a inclusão) Social como sendo aquela que não é a Tecnologia (da e para as empresas) que tenho denominado, para marcar a distinção, Convencional. E, em consequência, para implementar processos de Adequação Sociotécnica a partir da desconstrução da TC mediante a qual eles se estruturam.

44 O conceito de marco tecnológico (deve ser entendido como o marco que diz respeito à tecnologia e não como o marco do tecnólogo) busca analisar a interação entre os atores sociais (indivíduos, organizações), e não os atores sociais propriamente ditos a partir de uma perspectiva sociotécnica.

45 O marco tecnológico de um determinado grupo social está relacionado ao conceito de atribuições de significados que estrutura a sua gramática. Esta gramática é usada na interação de membros de um mesmo grupo social, resultando na atribuição compartilhada de significados. Quando os membros de um grupo social compartilham da mesma gramática, esse grupo é identificado como um grupo social relevante: um conjunto de indivíduos que conferem um mesmo significado a um determinado artefato.

46 A leitura possibilitada pela gramática de cada grupo (ou mesmo de diferentes indivíduos dentro de cada grupo) a respeito de um mesmo artefato pode ser distinta. O que gera artefatos semanticamente distintos ( "flexibilidade interpretativa"). Ocorre, então, um processo de negociação entre os diversos grupos, influenciado pela arquitetura de poder e pelas alianças estabelecidas entre eles. Finalmente tem-se o "fechamento", momento em que o significado do artefato é outorgado pelo(s) grupo(s) social(ais) que obteve (obtiveram) maior sucesso ao longo do processo de negociação. 
Os conceitos de instrumentalização primária e secundária provêm da leitura acerca da abordagem crítica da tecnologia baseada na reflexividade deste conceito, realizada por Feenberg. Ele incorpora a Marcuse, recorre ao construtivismo (enfoque sociotécnico) e à teoria da comunicação de Habermas para mostrar a essência da tecnologia como histórica e reflexiva. Ele realiza em relação à tecnologia algo semelhante ao que se pode fazer com outras instituições sociais do capitalismo. Isto é, entender e criticar a maneira como sua racionalidade responde a valores e interesses particulares.

Decorre dessa leitura a proposição de que quando o projeto técnico for submetido a exigências democráticas, ocorrerão profundas mudanças sociotécnicas nas atividades de concepção dos artefatos tecnológicos.

De fato, no trabalho em que mais detalhadamente trata esses conceitos, Feenberg declara que "Precisamos de um método que possa apreciar tais situações, mesmo que sejam poucas, mesmo se não pudermos avaliar seu sucesso(...)" e, depois, complementa "Este trabalho tentou criar uma estrutura teórica para isto".

Sobre as propriedades reflexivas da prática técnica, ele inicia afirmando que a tecnologia (capitalista, agrego eu), como todas as instituições sociais, tem propriedades reflexivas. Muito embora isso não seja reconhecido devido à sua identificação com uma ideologia especial (imune à reflexibilidade) que naturaliza suas características (de novo, agrego eu, capitalistas). Baseando-se em Habermas, ele afirma que a essência da tecnologia não é formada apenas por construtos conceituais extra-históricos. Esses construtos (determinações compartilhadas por qualquer tecnologia) devem ser considerados como uma essência anterior à história. São abstrações das várias essências historicamente concretas da tecnologia em seus diferentes estágios, o que inclui o seu atual estágio moderno.

As várias racionalidades técnicas que apareceram no curso da história seriam, cada uma delas, caracterizadas por um viés formal (racionalização secundária) que se associa à sua configuração específica (racionalização primária). Mas sua essência não é formada por aspectos sócio-históricos (Habermas). Esses construtos (determinações compartilhadas por qualquer tecnologia) devem ser considerados como uma essência "anterior", no sentido analítico, à história. Eles devem ser entendidos como abstrações das várias essências historicamente concretizadas (tecnologias) que foram concebidas ao longo de uma trajetória que inclui o estágio moderno e o contemporâneo.

A existência desses construtos é o que permite a formulação do conceito de "instrumentalização primária". O processo de sua combinação 
com atributos que se desenvolvem historicamente, conformando um todo, que se nos apresenta como um artefato tecnológico dado, é a "instrumentalização secundária”. As propriedades reflexivas da tecnologia fazem com que ela se manifeste através desses atributos e apareça como inseparável do seu contexto social e natural que os condiciona. Exemplos desses atributos são as formas estéticas, a organização do trabalho, os requisitos de capacitação profissional e outras propriedades relacionais dos artefatos.

Esses atributos reflexivos só se explicitam (ou, analiticamente, incorporam-se) quando da "instrumentalização secundária". O que faz com que passem a mostrar configurações associadas a distintas eras da história da racionalidade técnica.

Para mostrar que as características da tecnologia (capitalista, agrego eu) não são anteriores à historia, mas são combinações de construtos "primários" (abstrações) com atributos cuja existência se configura a partir de estágios historicamente concretos de uma trajetória, Feenberg dissocia analiticamente o processo de construção sociotécnica.

São eles: a INSTRUMENTALIZAÇÃO PRIMÁRIA, que explica a constituição dos objetos e sujeitos da ação técnica abstraindo-os de seu ambiente sociotécnico; e a INSTRUMENTALIZAÇÃO SECUNDÁRIA, que explica como, na prática (e ao longo de uma trajetória qualquer), realizam-se as ações entre sujeitos e objetos da ação técnica em diferentes ambientes sociotécnicos.

O quadro a seguir permite a comparação dos dois processos pela via dos seus quatro momentos, tendo em vista a forma como se processa a ação técnica entre os entre sujeitos e objetos com ela envolvidos.

\section{Instrumentalização Primária}

\section{Descontextualização}

A (re)construção de objetos naturais como objetos técnicos demanda "desmundializá-los", separando-os artificialmente do contexto no qual se encontram e são observados. Isolados, podem ser analisados em termos da utilidade de suas partes. As inovações aproveitarão qualidades de coisas naturais (faca: o agudo de pedra; roda: o redondo de fatia de árvore). Tais propriedades (agudeza, redondeza) são separadas de suas formas de ocorrência na natureza e vistas como propriedades técnicas.

A tecnologia é constituída a partir destes fragmentos de natureza que, após serem abstraídos de todos os seus contextos específicos, aparecem com uma forma útil. 


\begin{tabular}{|c|c|c|}
\hline & $\begin{array}{c}\text { INSTRUMENTALIZAÇÃO } \\
\text { PRIMÁRIA }\end{array}$ & $\begin{array}{c}\text { INSTRUMENTALIZAÇÃO } \\
\text { SECUNDÁRIA }\end{array}$ \\
\hline & DIFERENCIAÇÃO & CONCRETIZAÇÃO \\
\hline $\begin{array}{l}0 \\
\text { B }\end{array}$ & $\begin{array}{l}\text { DESCONTEXTUALIZAÇÃO: } \\
\text { separação artificial dos objetos } \\
\text { naturais de seus contextos originais }\end{array}$ & $\begin{array}{l}\text { SISTEMATIZAÇÃO: reinserção dos } \\
\text { objetos técnicos num dado ambiente } \\
\text { mediante a produção de artefatos }\end{array}$ \\
\hline $\begin{array}{l}E \\
T \\
0\end{array}$ & $\begin{array}{l}\text { REDUCIONISMO: os objetos são } \\
\text { reduzidos aos seus aspectos } \\
\text { tecnicamente utilizáveis }\end{array}$ & $\begin{array}{l}\text { MEDIAÇÃO: mediações éticas e estéticas } \\
\text { se combinam com as características } \\
\text { técnicas dos objetos e reinserem-nos no } \\
\text { contexto social }\end{array}$ \\
\hline $\begin{array}{l}\text { S } \\
\mathbf{U} \\
\mathbf{J}\end{array}$ & $\begin{array}{l}\text { AUTONOMIZAÇÃO: a ação técnica } \\
\text { automatiza o sujeito dissipando ou } \\
\text { atrasando a resposta do objeto à sua } \\
\text { ação }\end{array}$ & $\begin{array}{l}\text { COMPREENSÃO: através de sua } \\
\text { capacitação profissional o usuário percebe } \\
\text { o impacto reverso que o objeto tem sobre } \\
\text { ele }\end{array}$ \\
\hline $\begin{array}{l}E \\
\text { I } \\
\text { T } \\
\text { O }\end{array}$ & $\begin{array}{l}\text { CONSENTIMENTO: a ação técnica } \\
\text { exige um "consentimento" do sujeito } \\
\text { em relação às tendências } \\
\text { materializadas do objeto para dele } \\
\text { obter o resultado que deseja }\end{array}$ & $\begin{array}{l}\text { INICIATIVA: ações do trabalhador/ } \\
\text { consumidor permitem revisar as } \\
\text { tendências incorporadas ao objeto e } \\
\text { alterar suas caracteristicas }\end{array}$ \\
\hline
\end{tabular}

\section{Reducionismo}

Processos mediante o qual as coisas "desmundializadas" são simplificadas e reduzidas aos aspectos que permitem sua incorporação a redes técnicas que faz com que uma fatia de árvore possa se tornar uma roda. Os aspectos tecnicamente úteis dos objetos, suas "qualidades primárias", podem ser reorganizados em torno de um interesse externo.

\section{Autonomização}

O sujeito da ação técnica se isola dos efeitos das ações técnicas. A ação técnica autonomiza o sujeito dissipando ou atrasando a resposta do objeto à ação (soco da arma ao matar um homem; zumbido do vento ao arremessar uma tonelada de aço pela estrada).

\section{Consentimento}

O sujeito da ação técnica não modifica as "leis" básicas dos seus objetos; eles as aceita e usa-as o seu favor. Toda a ação técnica é uma navegação que segue as tendências do próprio objeto para extrair resultados. O controle do trabalhador e do consumidor, através do design do produto, tem uma estrutura similar. Não se pode “operá-los" da mesma forma que se faz máquinas, mas pode-se influenciá-los a se encaixar em programas preexistentes. 


\section{Instrumentalização Secundária}

A técnica é fundamental e intrinsecamente social. Para entendê-la é necessário incorporar à análise a instrumentalização secundária, que opera nas dimensões da realidade onde a abstração (instrumentalização primária) foi primeiramente feita.

\section{Sistematização}

Combinação e sistematização de objetos técnicos (isolados e descontextualizados). Preparação para a reinserção dos mesmos num novo contexto, de forma a fazê-los funcionar para atender a um fim socialmente dado, como um dispositivo semelhante aos originalmente encontrados na natureza.

\section{Mediação}

Mediações éticas e estéticas suplementam os objetos técnicos simplificados com novas qualidades secundárias que os reinserem no contexto social. Nas sociedades tradicionais, a ornamentação dos artefatos e suas significações éticas são integradas e indistintas de sua produção e emprego. Nas sociedades industriais modernas, ocorre uma separação - artificial entre aspectos técnicos e considerações éticas e estéticas. No entanto, uma vez produzidos, os objetos e sistemas técnicos readquirem características éticas e estéticas.

\section{Compreensão}

A autonomização do sujeito técnico é superada pela compreensão que passa a ter do objeto em função da aquisição de uma capacitação profissional. O sujeito não está mais isolado dos objetos e se transforma devido à relação técnica que passa a ter com eles. Essa relação supera a contemplação passiva e a manipulação externa do objeto e envolve o trabalhador na realidade de seus objetos, corporalmente como sujeito e como membro de uma comunidade que ganha identidade através dele. Essa compreensão possibilitada pela capacitação técnica é o que permite ao sujeito sentir o impacto reverso do objeto mediante seu envolvimento com ele. Ela, entretanto, tende a ser obscurecida pelo trabalho assalariado, que substitui a perícia intrínseca, "de por vida", do produtor independente pelo emprego provisório sob controle administrativo.

\section{Iniciativa}

A iniciativa liberta o trabalhador/consumidor do controle técnico imposto pelo consentimento. A cooperação no trabalho, a apropriação de dispositivos e sistemas pelos usuários são alternativas ao controle 
administrativo. É possível reduzir a alienação mediante a substituição do controle vertical pela auto-organização e o reprojetamento.

\section{Para entender melhor...}

A instrumentalização secundária é o que permite a reintegração do objeto ao contexto, das qualidades primárias com as secundárias, do sujeito com o objeto, e da liderança com o grupo, por meio de uma prática reflexiva, que trata os objetos técnicos e a própria relação técnica como matéria-prima para formas mais complexas de ação técnica.

A passagem do ofício para a produção industrial, que ocorre pela via do crescimento da produtividade do trabalho foi uma mudança qualitativa ocorrida no âmbito da instrumentalização primária. Mas foi igualmente importante, a instrumentalização secundária, quando a concepção do produto e a organização do trabalho sofreram profunda transformação qualitativa. Essa transformação não é apenas um acréscimo a uma pré-social relação com a natureza. Ela marca a industrialização considerada em seu aspecto técnico.

A racionalidade técnico-científica que se instaura é, por definição, não social uma vez que exclui o social entendido como um empreendimento a serviço de um conjunto social (coletivo ou comunitário). Neutra, porque pretende representar um interesse cognitivo-instrumental amplo que ignora e se coloca acima de valores específicos de cada subgrupo da espécie humana. Formal, porque se apresenta como resultado de um processo de diferenciação pelo qual se abstraem os vários conteúdos aos quais serve de mediação. Em suma, os princípios técnicos podem ser abstraídos de qualquer conteúdo, ou seja, de qualquer interesse ou ideologia. No entanto, como tais, são meras abstrações: assim que entram no mundo real, concreto, assumem conteúdo social e histórico específico

Nesse sentido, a eficiência, definida como proporção entre entradas e saídas, aplica-se a qualquer sociedade, transcendendo a particularidade do social. Mas quando se aplica a noção de eficiência, tem-se que decidir que coisas admitem "entradas" ou "saídas", quem pode oferecê-las e adquiri-las e em que termos, o que considerar como custos e benefícios etc., como qualquer outro conceito, ele tem sua especificidade social em uma dada aplicação real.

A instrumentalização primária não deve ser entendida como implicando a classificação de conteúdos sociais particulares em formas universais. Ela envolve a caracterização daquelas formas que, quando são contextualizadas numa sociedade (capitalista, por exemplo), incorporam valores com ela coerentes (capitalistas). 
A essência de uma tecnologia pode ser entendida como o resultado das determinações que ocorrem em sua trajetória. As várias racionalidades técnicas que apareceram no seu curso seriam, cada uma, caracterizadas por um viés formal (instrumentalização secundária) que se associa, na origem, à sua configuração específica (instrumentalização primária).

É possível distinguir entre as normas morais "puras" que descrevem "possíveis interações entre o falar e o agir em geral" e normas legais que se "referem à rede de interações numa sociedade específica". Como expressão concreta de um povo num tempo e espaço particulares, as normas estão ligadas a uma concepção particular de vida ideal. Todo sistema legal é também expressão de uma forma particular de vida e não um reflexo do conteúdo universal de direitos fundamentais.

Pode-se entender isso através da ideia de "viés formal" de implementação. Sistemas tecnicamente racionais, embora referidos apenas a valores como eficiência e adequação cognitiva ao real, revelam nos projetos a que dão origem um conteúdo normativo implícito quando colocados em seu contexto social. Fronteiras disciplinares entre as humanidades e as ciências impediram que essas questões fossem tratadas em termos similares e que a tradição da Escola de Frankfurt não lograsse uma ampliação da sua crítica à tecnologia.

Considere-se um exemplo. Um teste culturalmente enviesado pode ser administrado corretamente a diferentes grupos raciais ou étnicos e favorecer deslealmente um deles às custas do outro. $O$ viés pode não estar presente na forma cotidiana de preconceito, nem tratar-se apenas de uma pressuposição dos que aplicam o teste. Ele é uma propriedade relacional do teste com o contexto social em que é aplicado, é consequência de suas propriedades formais. O viés cultural implícito (escolha da linguagem ou das questões supostamente familiares) pode distorcer o resultado ainda que não ocorra uma intervenção substantiva como a diminuição dissimulada de um grupo ou a requisitos que o excluam das posições a que o teste pretende dar acesso.

\section{A dimensão "Contexto socioeconômico"}

Esta seção trata do contexto socioeconômico dinâmico e, por isso, mutável, onde têm lugar as iniciativas que conduzem ao desenvolvimento de TS à criação de EESs.

Os processos que conformam esses contextos são descritos a partir de idealizações sobre como teriam eles transcorrido e sido esquematizados segundo uma perspectiva marxista. A apresentação que se faz a seguir, neste caso do processo de transição da economia não capitalista para a 
capitalista é uma sistematização - nada original, breve, grosseira, e enviesada pelo propósito deste trabalho - de fragmentos daquilo que sobre ele pode ser desenvolvido a partir dessa perspectiva.

Observando a relação entre a economia formal e a informal é fácil verificar que ela envolve a troca de insumos (matérias-primas) e produtos, por um lado, e capital e mão de obra, por outro. Para uma adequada consideração dos condicionantes que essa relação coloca para o desenvolvimento de TS, privilegio o entendimento da forma como se verifica no tempo essa relação. Em particular, os fluxos de capital entre as economias formal e informal.

É possível individualizar, na dinâmica capitalista, situações típicas limites e gradientes - associadas (ou desencadeadoras) ao trânsito do capital entre a economia formal e a informal. Elas seriam as responsáveis por "regular" processos que, idealmente, ter-se-iam verificado ao longo da expansão do capitalismo. Primeiramente no sentido da economia formal para a informal, mas que em função de mudanças ou gradientes relacionados a algumas variáveis dessa dinâmica podem ocorrer no sentido inverso.

A tipologia está composta por seis situações típicas:

1. Limite econômico: o capital se vai localizando em segmentos (ou atividades) econômicos com taxas de lucro decrescente. Os com taxas superiores ficam reservados para os "maiores" (com maior poder político etc.). Os não atrativos permanecem na periferia do capitalismo (economia informal).

2. Limite político: costumes e práticas culturalmente arraigadas impedem a legalização da propriedade privada dos meios de produção em alguns segmentos ou atividades (informais) e, assim, protegem-nos da penetração do capital.

3. Limite do econômico x político: o balanço entre lucratividade esperada e custo político de ingressar em "espaços não capitalistas" (mais afastados ou menos acessíveis) leva a que a economia informal possa subsistir até mesmo no espaço urbano.

4. Gradiente tecnológico: a disponibilidade de uma nova tecnologia capaz de tornar rentável um "recurso natural" (economia informal) transformando-o num "recurso econômico" é um determinante da lucratividade esperada e tende a provocar a expansão do capital para explorá-lo.

5. Gradiente regulatório ou de mercado: uma mudança na relação de preços do trabalho vivo (salário) x trabalho morto (meios de produção, 
matéria-prima) é um determinante da lucratividade esperada que provoca a expansão ou retração do capital.

6. Gradiente político: uma mudança na correlação de forças políticas, sobretudo se incide na estrutura legal, provoca a expansão ou retração do capital (para a economia informal).

\section{A dimensão "Adequação Sociotécnica"}

Adequação Sociotécnica (AST) pode ser preliminarmente entendida como um processo concernente a um equipamento associado ou não a uma tecnologia desincorporada, concebido no âmbito de um contexto sociotécnico de uma dada amplitude (desde uma fábrica até um segmento industrial ou o conjunto do tecido socioprodutivo de um país) a outro, submetido a condicionantes distintos (em especial ao da propriedade dos meios de produção).

Simetricamente ao que poderia ter sido denominado adequação técnico-econômica, mas ficou sendo conhecido como engenharia reversa ou, na América Latina, como "tropicalização", a AST pode, então, ser conceituada como uma adequação de tecnologias pré-existentes a situações distintas daquelas para as quais foram originalmente projetadas, como preço relativo dos "fatores de produção", condições culturais ou edafoclimáticas, dificuldade de acesso a insumos, tamanho e características dos mercados etc.

A AST é, então, entendida (e proposta), não apenas como uma adequação aos requisitos e finalidades de caráter técnico-econômico típicos de um dado ambiente produtivo submetido à lógica capitalista, como é usual cada vez que nele se concebe o conhecimento para a produção de um bem ou serviço. Ela incorpora aspectos de natureza social e ambiental até agora considerados como "externalidades" em processos (convencionais) de adequação técnico-econômica conduzidos em contextos submetidos à lógica da acumulação do capital. E, por isso, ou "por definição", ainda estão totalmente ausentes da "planilha de cálculo" (ou código técnico) utilizada pelos desenvolvedores de artefatos tecnológicos (pesquisadores, engenheiros etc.) na sua concepção.

Avançando na conceituação, pode-se dizer que a AST busca promover uma adequação (ou reprojetamento) do conhecimento tecnocientífico, incorporado em equipamentos e insumos (hardware), formas de organização da produção (orgware), ou sob a forma intangível e mesmo tácita de modelos mentais (software) usados para conceber e conduzir as atividades correspondentes aos dois elementos sociotécnicos anteriores. 
A AST se refere, então, a um conjunto de processos de desconstrução e reconstrução (reprojetamento) da tecnologia convencional (ou capitalista) ou, mais genericamente da tecnociência que temos. Ou de forma mais radical e coerente com a ideia de não neutralidade da tecnociência, a processos de descontaminação da tecnociência dos valores e interesses do capital, hegemônicos nos ambientes em que ela é concebida, e sua "recontaminação" com os da ES.

Ela se diferencia da Construção Sociotécnica, tal como ela pode ser entendida a partir da contribuição dos pesquisadores do campo, por supor a existência de um contexto sociotécnico caracterizado por condicionantes distintos daqueles a que eles - implícita ou explicitamente - se referem. Em especial, o relativo à propriedade privada dos meios de produção, ao parecer percebido como pouco relevante na indução de características ao artefato resultante de processos de Construção Sociotécnica.

A AST foi concebida como um processo que tem por objetivo o desenvolvimento de TS. Mas ela pode ser entendida, não para fins de intervenção no movimento social concreto que em torno dela se organiza (para desenvolver TS), mas para operar o momento de reflexão teórica e elaboração conceitual, da maneira radical que a ele convém, elaborada em outro documento.

Nesse livro, conceituo a TS como o resultado da ação de um coletivo de produtores sobre um processo de trabalho que, em função de um contexto socioeconômico (que engendra a propriedade coletiva dos meios de produção) e de um acordo social (que legitima o associativismo), os quais ensejam, no ambiente produtivo, um controle (autogestionário) e uma cooperação (de tipo voluntário e participativo), permite (a ação referida) uma modificação no produto gerado passível de ser economicamente apropriada segundo a decisão do coletivo.

A AST visa a adequar a tecnologia convencional (e, inclusive, conceber alternativas como indicadas pelas suas sete modalidades) adotando critérios suplementares aos técnico-econômicos usuais e aplicando-os a processos de produção e circulação de mercadorias em redes de ES visando a otimizar suas implicações sociais, econômicas e ambientais.

Como se pode perceber, mesmo no caso em que se esteja analisando uma TS "nova”, que aparentemente não derive de uma adaptação de uma tecnologia convencional, há que ter em mente que o seu desenvolvimento demandou uma adequação do conhecimento tecnocientífico previamente existente ao novo contexto sociotécnico em que ela se está inserindo. 
As sete modalidades de AST, apresentadas a seguir, podem ser entendidas como momentos (o que é diferente de estágios) sucessivos ou não, de um processo contínuo de adequação que tem lugar num dado empreendimento solidário na presença de alguns elementos distintos daqueles que caracterizam o contexto mais abrangente que tem como núcleo a propriedade privada dos meios de produção.

\section{Alteração na distribuição da receita gerada}

A manutenção das características do processo de trabalho (uso convencional das máquinas, formas de organização do trabalho etc.) em situações em que a propriedade dos meios de produção, já empregados antes no caso de fábricas recuperadas, passe de privada à coletiva, propiciando a alteração na distribuição da receita gerada (de lucro e salários para retiradas), promove uma modificação no contexto sociotécnico e é um embrião de novas ASTs.

\section{Apropriação}

A propriedade coletiva dos meios de produção (em cooperativas novas ou que sucederam a empresas falidas) supõe a aquisição, pelos trabalhadores, de conhecimento produtivo (encadeamento da produção, possibilidades de adensamento, completamento ou extensão da cadeia etc), de gestão, e de concepção de produtos e processos, sem que alguma modificação seja introduzida nos mesmos. Distingue-se do conceito usual de "apropriação" do conhecimento tecnocientífico na medida em que tem como condição a propriedade coletiva dos meios de produção.

\section{Repotenciamento}

A postura associada à nova condição de propriedade coletiva tende a levar à modificação das máquinas e equipamentos mediante ajustes, recondicionamento ou revitalização (incorporação de componentes e dispositivos mais recentes), procedimentos de manutenção preventiva etc. visando ao aumento da sua vida útil ou à modificação das características do bem ou serviço produzido.

\section{Ajuste do processo de trabalho}

Um ambiente de trabalho democrático e participativo, não submetido ao controle capitalista, levará ao questionamento da divisão técnica do trabalho. Semelhantemente ao que ocorre quando da substituição do modelo fordista-taylorista pelo toyotista (em função de uma mudança na base técnica e sem alteração da forma de propriedade dos meios de 
produção), o processo de trabalho tenderá a assumir formas de organização autogestionárias.

\section{Alternativas tecnológicas}

Lembrando a ideia de momentos, associada à AST, entende-se esta modalidade como decorrente da percepção de que as anteriores não são suficientes para dar conta das demandas dos EESs. Ela implica a busca e seleção alternativas tecnológicas já existentes, distintas da tecnologia convencional - anteriormente utilizada ou disponível no mercado mediante consultas a pessoas, instituições, bancos de dados etc.

\section{Incorporação de conhecimento tecnocientífico existente}

O prolongamento do processo de busca de tecnologias alternativas tenderá a explicitar a necessidade de incorporar conhecimento (intangível, não embutido em meios de produção) existente, para o desenvolvimento de tecnologias (novos processos produtivos, meios de produção, insumos etc.). Esta modalidade implica atividades de "inovação incremental", que tenderão a ocorrer de forma associada a instituições públicas de $\mathrm{P} \& \mathrm{D}$ e ensino.

\section{Busca de conhecimento tecnocientífico novo}

O prolongamento do processo de inovação incremental tenderá a explicitar a necessidade de incorporar às atividades realizadas nos EESs resultados da exploração da "fronteira" do conhecimento tecnocientífico. Esta modalidade implica atividades de "inovação radical" que provavelmente demandarão o concurso de instituições públicas de $\mathrm{P} \& \mathrm{D}$ e ensino. 